
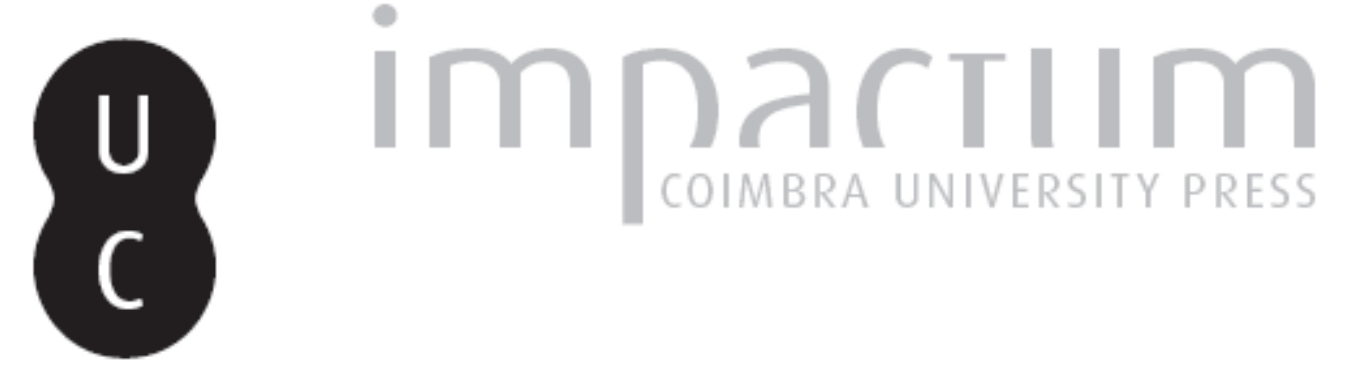

\title{
Algumas reflexões sobre os temas da origem da morte, do estatuto ontológico do defunto e da escatologia universal no capítulo 175 do «livro do mortos»
}

\author{
Autor(es): $\quad$ Silva, André de Campos
}

Publicado por: Centro de História da Universidade de Lisboa

URL persistente:

URI:http://hdl.handle.net/10316.2/23714

DOI:

DOI:http://dx.doi.org/10.14195/0871-9527_20_3

Accessed : $\quad$ 26-Apr-2023 15:20:58

A navegação consulta e descarregamento dos títulos inseridos nas Bibliotecas Digitais UC Digitalis, UC Pombalina e UC Impactum, pressupõem a aceitação plena e sem reservas dos Termos e Condições de Uso destas Bibliotecas Digitais, disponíveis em https://digitalis.uc.pt/pt-pt/termos.

Conforme exposto nos referidos Termos e Condições de Uso, o descarregamento de títulos de acesso restrito requer uma licença válida de autorização devendo o utilizador aceder ao(s) documento(s) a partir de um endereço de IP da instituição detentora da supramencionada licença.

Ao utilizador é apenas permitido o descarregamento para uso pessoal, pelo que o emprego do(s) título(s) descarregado(s) para outro fim, designadamente comercial, carece de autorização do respetivo autor ou editor da obra.

Na medida em que todas as obras da UC Digitalis se encontram protegidas pelo Código do Direito de Autor e Direitos Conexos e demais legislação aplicável, toda a cópia, parcial ou total, deste documento, nos casos em que é legalmente admitida, deverá conter ou fazer-se acompanhar por este aviso.

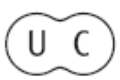




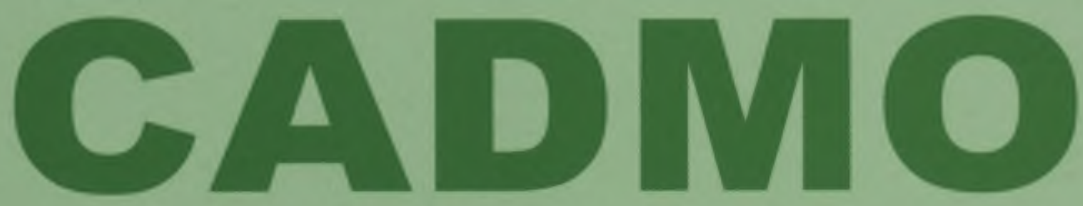

Revista de História Antiga

\author{
Centro de História \\ da Universidade de Lisboa
}

\title{
20
}

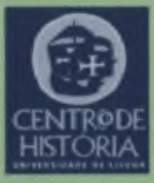

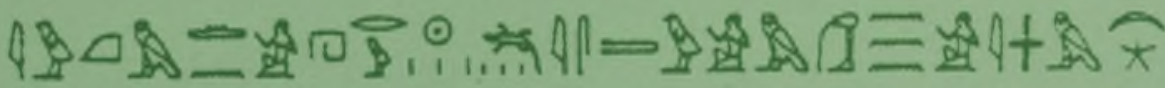

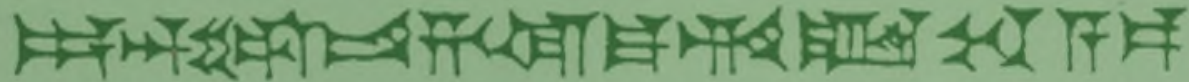

MHNIN AEI $\Delta$ E $\Theta E A ~ \Pi H \Lambda H I A \triangle E \Omega$ 


\title{
ALGUMAS REFLEXÕES SOBRE OS TEMAS DA ORIGEM DA MORTE, DO ESTATUTO ONTOLÓGICO DO DEFUNTO E DA ESCATOLOGIA UNIVERSAL NO CAPÍTULO 175 DO «LIVRO DO MORTOS»
}

\author{
ANDRÉ DE CAMPOS SILVA \\ Universidade de Lisboa \\ andre.silva.tvd@gmail.com
}

\section{Resumo}

O capítulo 175 do "Livro dos Mortos" aborda três temas de grande relevância para o estudo da cultura egípcia: a morte, as condições de existência do defunto no Além, e o regresso do mundo ao caos. Com este artigo pretende-se contextualizar e interpretar estes três tópicos.

Palavras-chave: Atum; Ré; Osíris; Set; filhos de Nut; izft, desmembramento social; nhhh e $\underline{d} t$, serpente.

\section{Abstract}

In spell 175 of the Book of the Dead three themes of great relevance to the study of Egyptian culture are addressed: death, conditions of existence in the afterlife, and the return of the world to chaos. This article is intended to contextualise and interpret these topics.

Key words: Atum; Re; Osiris; Seth; children of Nut; izft, social dismemberment; $n h \underline{h} \underline{h}$ and $\underline{d} t$; serpent. 
De entre um total de 192 capítulos do chamado "Livro dos Mortos"(1) há alguns que se destacam pela sua profundidade humanista. É o caso do capítulo $175^{(2)}$, que aborda três temas de grande relevância para o estudo da cultura egípcia: morte de Osíris, definição das condições de existência do mesmo deus no Além, e escatologia universal. Apesar de o capítulo 175 incluir outros tópicos, a nossa reflexão incidirá apenas sobre estes três.

O capítulo $175^{(3)}$ abre com o defunto, identificado com Atum, a dirigir-se ao deus Tot:

"Ó Tot, o que é isto que se passou através dos filhos de Nut (msw $n w t)$ ? Eles fizeram a guerra (hrwyw). Eles causaram distúrbios ( $h n n w)$. Quando fizeram o mal (izft), criaram a rebelião (sbiw). Quando fizeram matanças $\left(\check{s}^{\prime} w\right)$, criaram o aprisionamento (sswt). De facto, converteram tudo o que era grande em tudo o que é pequeno de entre tudo o que eu fiz. Saudação (?), ó grande Tot» - diz Atum.

Tot:

"Não verás mal (izft). Não sofrerás. Encurta os seus anos, adianta os seus meses, dado que eles traíram os segredos em tudo o que fizeste." Osíris N:

"Minha é a tua paleta, ó Tot. A ti trouxe o teu tinteiro. Eu não estou entre aqueles que traem os seus segredos. Nenhum dano será feito por mim.» ${ }^{(4)}$

\section{Filhos de Nut e morte de Osíris}

Não é claro a quem se refere a expressão "filhos de Nut». Aparentemente trata-se de um termo flexível que pode incluir diversas divindades conforme o contexto em que ocorre. Com efeito, é importante tomar em linha de consideração que muitos dos elementos do universo mitológico egípcio são polissémicos ${ }^{(5)}$. Assim, na Grande Enéade de Heliópolis os filhos de Nut são: Osíris, Ísis, Set e Néftis ${ }^{(6)}$. Mas estes podem também ser estrelas, como arguiu László Kákosy ${ }^{(7)}$, e como podemos verificar neste passo da biografia do sacerdote de Onuris Anhurmés (reinado de Merenptah, 1213-1203 a. C.):

O meu senhor diz: "Ficarás para sempre em Behedet." [Possa ele fazer com que] o meu nome seja [estabelecido] como o horizonte; é dia como a noite dos filhos divinos, (pois) o meu nome nasce quando os filhos de Nut retrocedem. ${ }^{(8)}$ 
Neste contexto o retroceder dos filhos de Nut será certamente uma metáfora para o amanhecer, pelo que o termo não é usado com a mesma conotação que lhe está imbuída no capítulo 175. No entanto, existe uma constelação associada a Set e à morte de Osíris. Trata-se da constelação identificada com a Ursa Maior. Era designada em Egípcio de mshtyw, representando umas vezes uma enxó (que em Egípcio era igualmente mshtyw), e outras vezes uma perna dianteira de um touro $(h p s)^{(9)}$. Enquanto $h p s ̌$, esta constelação simbolizava a arma com que Set matava os seus inimigos ${ }^{(10)}$. Sabemos pela fórmula 580 dos "Textos das Pirâmides" que foi sob a forma de um touro que Set matou Osíris:

Meu pai Osíris, este Pepi. Eu abati por ti aquele que te abateu sob a forma de um touro (it(.i) wsir ppy pn hwwi.n(.i) n.k hawi tw $m$ iḥ $)^{(11)}$.

Herman te Velde menciona ainda que no Papiro de Leiden $\mathrm{I}^{(12)}$, provavelmente da XIX dinastia (1295-1186), Set mata Osíris não só sob a forma de um touro, mas com a pata dianteira hpš. No capítulo 17 do "Livro dos Mortos" os quatro filhos de Hórus são destacados para guardar a constelação mshtyw, enquanto arma de Set ${ }^{(13)}$. O Papiro Jumilhac, do IV século a.C., acrescenta que Hórus cortou a pata dianteira hpš de Set, na sua forma de touro, e de seguida a atirou para o céu do Norte formando, deste modo, a constelação mshty ${ }^{(14)}$. Se esta etiologia já estava implícita no capítulo 17 do "Livro dos Mortos", é interessante verificar que a arma de Set continua a constituir uma ameaça para Osíris mesmo depois de este já ter sido morto. De facto, no capítulo 175 o aprisionamento de Set parece indicar precisamente que Osíris permanece em risco de ser atacado pelo irmão:

Enviei o ba ${ }^{(15)}$ de Set distinto de todos os deuses. Fiz com que o seu ba esteja sob guarda na barca através do desejo de que ele não assuste os membros dos deuses." ${ }^{(16)}$

Como reparou Te Velde, vários textos indicam que Set procura destruir o corpo do defunto, sendo o uso da máscara funerária um dos métodos para evitar a profanação do cadáver por Set numa clara analogia ao desmembramento de Osíris ${ }^{(17)}$, que no capítulo 175 parece ser extensível aos restantes deuses. Dada a importância da identidade e estatuto social entre a elite do antigo Egipto, quer através da perpetuação do nome, quer através da preservação física do corpo, Set representava assim a ameaça e o medo da destruição do corpo e do consequente anonimato de que o defunto seria vítima ${ }^{(18)}$. 
Os filhos de Nut no capítulo 175 serão portanto Set, a sua arma simbolizada pela constelação mshtyw, e Osíris. A morte deste último e a ameaça de que seja novamente atacado por Set parecem ser os "distúrbios" a que Atum se refere no começo do capítulo. Como nota Sherine El-Sebaie ${ }^{(19)}$, se de facto a referência é ao conflito entre Set e Osíris, é possível que as contendas entre Hórus e Set, que consistem na luta pela sucessão ao trono deixado vazio pela morte de Osíris, estejam também implícitas no lamento de Atum, o que parece ser confirmado pelo seguinte passo:

"O teu trono pertence ao teu filho Hórus" - diz Atum. "Ele vai agora enviar os anciões. Ele vai agora governar as Duas Margens. Ele vai herdar o trono que está na Ilha das Chamas ${ }^{(20) . »(21)}$

No capítulo 175 o termo "filhos de Nut» aplicar-se-á, assim, apenas a estes deuses e não à primeira geração da humanidade como sugere Jacobus van Dijk ${ }^{(22)}$. Deste modo, é possível que o tempo que precede os conflitos no seio da geração de Nut corresponda a uma Era Dourada ${ }^{(23)}$. Por via da morte de Set por Osíris - um dos corolários dos referidos conflitos - esta mesma Era Dourada chega ao seu fim. Embora Erik Hornung ${ }^{(24)}$ atribua a origem do mal ao caos primordial, inferindo por conseguinte que os deuses não podem ser responsabilizados pelo mal no mundo, o mal (izft(25)) surge aqui como responsabilidade das divindades ${ }^{(26)}$. E é interessante verificar que Atum não responsabiliza apenas Set, mas também Osíris.

$\mathrm{Na}$ cultura egípcia não parece haver uma sistematização da origem do mal. Exemplo disso é a fórmula 1130 dos "Textos dos Sarcófagos» ${ }^{(27)}$ que, por um lado, atribui a origem do mal (izft) à desobediência dos homens ao deus criador $^{(28)}$, mas, por outro, se refere à oposição de entidades divinas à barca solar ${ }^{(29)}$. Por conseguinte, podemos interpretar os conflitos entre os filhos de Nut não como a origem do mal mas sim como uma das suas origens.

\section{Estatuto ontológico de Osíris}

De modo similar, a morte de Osíris, que no capítulo 175 não é descrita mas sugerida, não dirá respeito à origem da morte ${ }^{(30)}$ mas será antes um modelo arquetípico ou um paradigma da morte. Neste sentido, Osíris é o representante universal, ou arquétipo, do defunto. 
Após morrer e entrar na Duat, o mundo dos mortos egípcio, Osíris inicia um diálogo com Atum onde irão ser reveladas as condições de existência de Osíris:

Palavras ditas pelo Osíris $\mathrm{N}$ :

"Ó Atum, o que significa isto? Estou a partir para o deserto, a Terra do Silêncio."

«Não tem água, não tem ar, funda, funda, escura, escura, sem limites, sem limites, onde viverás na paz de coração da Terra do Silêncio. Prazeres sexuais não serão nela desfrutados; mas o estado de 3 h $w^{(31)}$ é-te dado em troca de água, ar, e prazer sexual, e paz de coração em troca de pão e cerveja” - Assim falou Atum. ${ }^{(32)}$

$\mathrm{Na}$ definição do estatuto ontológico do morto, o texto identifica os elementos mais prezados em vida e que passam a estar ausentes na transição para a vida após a morte. O próprio nome "Terra do Silêncio» é indicador de uma transição brusca e isolante. O primeiro elemento cuja ausência é notada pelo defunto é, portanto, o convívio com outros seres humanos. Outra ausência importante é o prazer sexual. Para a referência do ar e da água podemos fazer uma leitura simbólica, e identificar ambos com aspectos essenciais à vitalidade. A chamada "cerimónia de abertura da boca", por exemplo, em que os órgãos vitais do defunto mumificado são ritualmente reactivados, tem como um dos seus propósitos devolver ao defunto a capacidade de respirar e de se alimentar ${ }^{(33)}$. No caso do prazer sexual, a palavra empregue no texto, ndmmyt - cuja raiz é ndm (“doce», «agradável»(34)) -, exclui, a meu ver, essa leitura. Apesar da conotação simbólica de ar e água, todos os elementos negados ao morto no Além têm igualmente uma forte componente de satisfação sensorial. O defunto é assim obrigado a trocar o conforto proporcionado pelos aspectos materiais por um desenvolvimento espiritual que, pela frustração demonstrada pelo defunto, se diria quase ascético.

O texto deixa assim subentendido que o defunto não vai necessariamente para melhor. Como demonstrou Jan Assmann, este passo está em consonância com várias inscrições funerárias ${ }^{(35)}$ onde a morte do defunto é profundamente lamentada por este abandonar não só as comodidades da vida terrena, mas também, e talvez acima de tudo, por deixar a família e o seu círculo de intimidade social ${ }^{(36)}$. Esta quebra de contacto social tem sido por vezes referida como "desmembramento social", em comparação com o desmembramento físico de que Osíris é vítima - uma semelhança decerto notada pelos antigos Egípcios ${ }^{(37)}$. 
A separação da sociedade é, no capítulo 175 , simbolizada pelo afastamento de Osíris da barca solar:
Osíris:
«É demasiado para mim, meu senhor, não ver o teu rosto. De facto, não vou sofrer a tua falta. Mas todos os deuses tomaram o seu trono na barca de Milhões (de Anos).”
Atum:
"O teu trono pertence a Hórus" - diz Atum. "Ele vai agora enviar os anciões. Ele vai agora governar as Duas Margens. Ele vai herdar o trono que está na Ilha das Chamas.»
Osíris:
"Então ordena que o deus veja o seu igual, pois o meu rosto verá o rosto de Atum."(38)

Como nota ainda Assmann, o discurso pessimista sobre a morte e o Além surge mais intensamente após o reinado de Akhenaton (1364-1347): "Firm belief in immortality made it impossible to include songs expressive of pain and sadness, songs that would have immortalized the negative side of death and the realm of death. In the immediate wake of the Amarna period, however, this taboo was lifted, and the texts sound an entirely new note expressive of pain and sadness. In them we encounter the image of death as reversal.»(39)

As considerações de Assmann reportam-se sobretudo ao discurso explícito ${ }^{(40)}$. Em dois túmulos do Império Antigo (2686-2160 a. C.) encontramos breves referências a esta concepção negativa da existência no mundo dos mortos $^{(41)}$, e a necessidade da inscrição dos "Textos das Pirâmides" - um compêndio de fórmulas mágicas destinadas a possibilitar ao rei a ascensão ao domínio celeste - a partir do fim da $V$ dinastia ${ }^{(42)}$ sugere igualmente a ideia de que esta concepção remonta pelo menos ao Império Antigo.

Independentemente da data de início das reflexões dos antigos Egípcios sobre este tema, a literatura mortuária não se limitou a providenciar ao defunto guias para sobreviver aos seres hostis - incluindo tanto habitantes da Duat como deuses -, mas investiu igualmente em sortilégios destinados a devolver ao defunto os prazeres da vida na terra. Deste modo, encontramos na fórmula 576 dos "Textos dos Sarcófagos" a seguinte indicação:

Em relação a todo o homem que venha a conhecer esta fórmula, ele pode copular nesta terra de noite e de dia [...]. Palavras a serem ditas sobre uma conta de cornalina ou ametista. Colocar no 
braço direito do akh (ir s $n b$ rh.t $t(y) . f(y) r(3)$ pn iw.f nk.f $m$ t3 pn $m$ grh

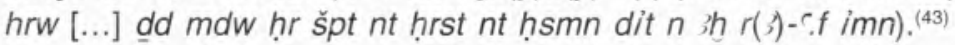

O capítulo 110 do "Livro dos Mortos" destina-se igualmente a reproduzir a vida na terra nos Campos de laru:

Início das fórmulas para o Campo de Oferendas, as fórmulas para sair de dia, entrar e sair do domínio do deus, alcançar os Campos de laru, existir no Campo de Oferendas, [...], comer lá, beber lá, copular lá, fazer tudo o que é feito sobre a terra. ${ }^{(44)}$

Vemos assim como na literatura funerária egípcia convivem dois tipos de discurso opostos. Apesar da sua dissonância, creio que estão envolvidos numa relação dialéctica. A visão de que o Além é um lugar de solidão, ascetismo, e constante ameaça de se morrer uma segunda vez, pode ser a justificação para que todo um aparato - desde a preparação adequada do túmulo e do defunto ao investimento em fórmulas e rituais de teor mágico-religioso (como o capítulo 175 cujo título é justamente «Fórmula para não morrer outra vez»(45)) - seja mobilizado para compensar as condições de existência no outro mundo ${ }^{(46)}$. Aparato esse que, por sua vez, reforça a visão pessimista que se tem desse mundo - gerando por conseguinte um ciclo vicioso.

\section{Escatologia universal}

Mas no capítulo 175 não se define apenas o estatuto ontológico do deus Osíris. É também abordado o tema do regresso do mundo ao estado prévio à sua ordenação:

"Qual é o meu tempo ( $\left.h{ }^{\top} w\right)$ de vida?" - diz Osíris.

"Serás por milhões de milhões (de anos), uma vida ( $h(w)$ de miIhões ${ }^{(47)}$. Depois vou destruir tudo o que fiz (iw.i grt hadi ir.t.n.i nbt). Esta terra vai regressar ao Nun, à Inundação, como no seu início (iw t3 $p n r i i[t] m n w m$ hwhw mi tpy.f- $(w))$. Sou eu que permanecerei juntamente com Osíris, tendo feito as minhas transformações em outras serpentes que a humanidade não vai conhecer, nem os deuses ver.

Este passo não é inteiramente claro em relação às suas implicações. A sobrevivência de Atum e de Osíris leva-nos a questionar o propósito da continuidade de ambos os deuses, se se considera a hipótese de uma recriação, e qual a importância deste passo no capítulo 175. 
Antes de analisar este texto, proponho a análise de dois textos que o precederam e que, por conseguinte, poderão servir de base contextual para a sua interpretação.

O paralelo mais próximo encontrar-se-á na já citada fórmula 1130 , em que se lê:

$\mathrm{Fiz}^{(48)}$ milhões de anos entre mim e aquele que tem o coração cansado ${ }^{(49)}$, o filho de Geb (Osíris). Depois sentar-me-ei com ele num só lugar, e colinas tornar-se-ão cidades, e cidades tornar-se-ão colinas. A mansão vai desolar a mansão (iw ir.n.i ḥhw nw rnpwt m-imytw.i $\{m\}$ $r$ wrd ib pf z' gb hmsi.ks.i hnn .f $m$ st w ${ }^{\left.4 t^{50}\right)}$ iw iswt $r$ niwwt iw niwwt $r$ iswt in hwwt wš.s hiwt $\left.{ }^{(51)}\right){ }^{(52)}$

Tal como no capítulo 175, Atum junta-se a Osíris após milhões de anos, e o mundo ordenado chega ao seu fim. A palavra ist, além de significar "colina", tem também o significado de "ruína»(53), o que reforça a ideia de destruição. Em duas das seis versões recolhidas por Adriaan de Buck, a frase iw ir.n.i precede a sentença "colinas tornar-se-ão cidades... ${ }^{(54)}$, reforçando assim a ideia de que esta destruição é iniciada por Atum. Que esta frase tem conotações de devastação é confirmado pela Profecia de Neferti, em que na descrição do estado conturbado do Egipto é dito: "a água torna-se margem do rio, I e a margem do rio torna-se água.»(55) Relativamente à última frase, o sujeito gramatical é identificado através da construção-in como ḥwt $t^{(56)}$. Este termo tem também os significados de "templo" ou "palácio» (57). É portanto possível que o fim do mundo ordenado seja descrito por analogia a uma guerra civil, talvez tendo como referência os conflitos que deflagraram durante o Primeiro Período Intermediário (c. 2160-2055 a. C.) $)^{(58)}$.

Outro possível paralelo do capítulo 175 provém da Instrução para o Rei Merikaré:

Uma geração de mortais sucede-se a outra,

Mas deus, que tudo conhece, escondeu-se.

Não há quem resista ao poder do senhor da mão,

Pois é ele quem pode / restringir o que os olhos vêem. ${ }^{(59)}$

Estas sentenças parecem ser precursoras do que é dito no capítulo 175. A divindade referida em Merikaré através do termo genérico "deus" trata-se, provavelmente, de um deus de características solares ${ }^{(60)}$. Por conseguinte, o epíteto "senhor da mão" reporta-se, muito provavelmente, ao deus Atum ${ }^{(61)}$. O poder de Atum a que ninguém 
pode resistir lembra-nos a capacidade de Atum destruir a sua criação no capítulo 175 e na fórmula 1130. Quanto ao facto de se esconder e à sua capacidade de "restringir o que os olhos vêem", parece-se muito com a sua transformação, no capítulo 175 , em serpentes que os homens não conhecerão e os deuses não verão. Segundo alguns autores, esta referência do capítulo 175 significa que nem os homens poderão conhecer as serpentes, nem os deuses vê-las, simplesmente por já não existirem ${ }^{(62)}$. Se for esta a concepção que está subjacente à declaração da Instrução para o Rei Merikaré, não só encontramos uma referência escatológica na literatura sapiencial, como podemos inferir que a capacidade de Atum destruir o mundo ordenado se trata de um dos seus atributos por definição( ${ }^{(63)}$.

Vemos assim como a escatologia universal mencionada no capítulo 175 tem antecedentes na literatura egípcia. Por conseguinte, creio que podemos partir do princípio de que o autor, ou autores deste capítulo tinham conhecimento destes precursores e conceberam esta escatologia tendo-os em linha de conta.

Procuremos agora responder às três questões acima colocadas: qual o propósito da sobrevivência de Atum e Osíris; se uma recriação do mundo está implícita; e finalmente, o porquê do tema da escatologia universal no capítulo 175. A união entre Atum e Osíris, que origina o fim do mundo ordenado, tem um paralelo na concepção da viagem contínua do deus Sol. Pelo menos desde o Império Médio (2050-1750)(64), o renascimento do Sol era metaforicamente atribuído à união entre o deus que o representa e Osíris. Com efeito, os antigos Egípcios interpretavam a aparente entrada do Sol no interior da terra como a sua descida ao espaço dos mortos. O Sol era personificado por várias divindades. No contexto da descida do Sol ao domínio dos mortos, Ré e Atum eram as mais relevantes. Se por um lado Ré representava o Sol no seu zénite, Atum, pelo contrário, representava o pôr-do-sol, isto é o Sol envelhecido e desgastado(65). Efectivamente, é um estado de fadiga, e de inércia(66), que caracteriza os que estão no submundo; Osíris e os seus restantes habitantes não estão verdadeiramente mortos, mas apenas sujeitos a este estado condicionante ${ }^{(67)}$. Embora um dos objectivos da descida de Ré a este espaço seja revitalizar os que o habitam ${ }^{(68)}$, incluindo Osíris, ele próprio necessita deste deus. Sendo o paradigma do deus que morreu, não só fisicamente mas também espiritualmente, e que foi posteriormente reanimado, Osíris é o deus que confere a Ré a capacidade de sair do submundo revigorado, como o declara um passo do já citado texto do cenotáfio de Seti I: «quando a 
majestade deste deus entra, está na sua primeira hora da noite, tornando-se novamente eficaz no abraço do seu pai Osíris»(69).

A união entre Ré e Osíris não se limita à dinâmica de morte e renascimento, mas estende-se ainda à concepção egípcia de tempo. Esta conexão é indicada pelas glosas do capítulo 17 do "Livro dos Mortos»:

Meu é o ontem, e eu conheço o amanhã.

Quem é ele? O "ontem" é Osíris; o "amanhã» é Ré. ${ }^{(70)}$

O mesmo capítulo acrescenta ainda:

Quanto "ao que existe" [...] significa $n h h h$ e $\underline{d}$ t. Quanto a $n h ̣ h$, é o dia; quanto a $d t$, é a noite. ${ }^{(71)}$

O dia está naturalmente conotado com o Sol (na língua egípcia esta relação é estreita, uma vez que tanto o nome do deus Ré como a palavra "dia" são $r$ ), e Osíris com a noite, isto é, a escuridão da Duat - o lugar a que está perpetuamente confinado. Por conseguinte, Osíris personifica o ontem e $\underline{d}$ t, enquanto Ré personifica o amanhã e $n h h$ ḥ. Estes são os dois conceitos usados para expressar a ideia que mais se aproxima à nossa concepção de "eternidade". Nḥh reporta-se a um tempo cíclico, dinâmico, e recorrente - caracterizado sobretudo pelo ciclo da sucessão do dia e da noite -, enquanto $d t$ representa um tempo estático cuja maior expressividade será a imortalidade do defunto(72). Como argumenta Jan Assmann ${ }^{(73)}$, estes dois conceitos podem estar estreitamente relacionados com a indicação de tempo na gramática egípcia. Esta não tem propriamente "tempos», mas antes "aspectos", referidos nas actuais gramáticas de egípcio como "perfectivo", e "imperfectivo» (74). O aspecto perfectivo indica acção completada, ao passo que o aspecto imperfectivo indica acção contínua e inacabada $^{(75)}$. Dt (perfectivo) representa assim, de uma forma linear, o tempo passado e completado. Inversamente, nḥh (imperfectivo) caracteriza o futuro que se desenrola por meio de eventos cíclicos.

Como nota ainda Jan Assmann ${ }^{(76)}$, a realidade só existe através da correlação entre Ré/nhḥ e Osíris/dt. O tempo cíclico precisa do tempo estático para se reciclar. E é justamente esta reciclagem que é interrompida quando Atum se une permanentemente a Osíris - no capítulo 175 apenas é dito que Atum se une a Osíris, mas a fórmula 1130 esclarece que a união se dá «num só lugar». Sem périplo solar e sem renovação do tempo cíclico, a existência de deuses e homens torna-se insustentável. 
Ao contrário da fórmula 1130 , que apenas refere a união de Atum e Osíris, o capítulo 175 acrescenta que a condição ontológica dos dois deuses sofre uma transformação. Ambos os deuses passam a existir sob a forma de serpentes ${ }^{(77)}$. Como repara Erik Hornung ${ }^{(78)}$, a serpente está particularmente associada ao oceano primordial indiferenciado. A existência só é possível através da nomeação, que diferencia um ser de toda a restante matéria deste oceano - o oposto, o anonimato, torna-o indiferenciado. Pela sua conotação de regeneração ${ }^{(79)}$, a serpente é das poucas formas de existência ${ }^{(80)}$ que permitem a diferenciação sem recurso ao suporte material do mundo ordenado. Por esta razão, foi a forma que o deus Atum adoptou quando o mundo ainda não tinha sido criado(81).

A formulação do regresso do mundo ao caos contém, portanto, todos os ingredientes para uma eventual recriação do mundo, nomeadamente a união entre Atum e Osíris - que é um claro paralelo, se não mesmo uma emulação, da união diária entre Ré e Osíris -, e a transformação dos dois deuses em serpentes - o que novamente nos remete para uma das formas de Atum enquanto deus criador. Note-se, no entanto, que apesar de estar implícita uma eventual recriação do mundo, nada no texto nos indica que esta se concretizará. Mas, como sugere E. P. Uphill( ${ }^{(2)}$ é também possível que os antigos Egípcios considerassem a hipótese de ocorrerem várias destruições e recriações do mundo.

Mas mesmo que haja uma recriação, por que razão decidiram os autores do capítulo 175 inserir a escatologia universal na literatura mortuária? O facto de que vários dos textos que compõem os três principais compêndios desta literatura - "Textos das Pirâmides", "Textos dos Sarcófagos", e "Livro dos Mortos" - serem provenientes de outros contextos ${ }^{(83)}$ pode em parte justificar a presença deste tema no capítulo 175. Porém, é improvável que o texto não fosse adaptado para o seu novo contexto. Talvez por isso mesmo, Atum garante a Osíris "uma vida de milhões" de anos; é possível que os autores do capítulo 175 sentissem alguma insegurança relativamente à possibilidade do fim do mundo - mesmo que esperassem uma eventual recriação, podiam não estar completamente convictos.

Apesar do motivo acabado de referir, penso que a principal justificação para o capítulo 175, assim como a fórmula 1130 e a Instrução para o Rei Merikaré, fazerem referência ao regresso do mundo ao caos informe se deve à própria percepção dos antigos Egípcios da sua evolução histórica. É difícil conceber que uma civilização que, até 
ao Império Novo, passou por dois períodos de agitação política e social, viu túmulos e templos - construídos em pedra para durarem o máximo de tempo possível - degradarem-se e serem pilhados, e que considerava que sem culto apropriado aos deuses e sem responsabilidade moral o mundo ficaria entregue ao caos, não tenha meditado sobre um eventual fim do mundo ${ }^{(84)}$.

Podemos portanto conjecturar que a escatologia universal foi mantida no capítulo 175 por os autores do "Livro dos Mortos" aceitarem o inevitável: que o sol um dia iria deixar de renascer.

\section{Conclusão}

O capítulo 175 é exemplificativo de algumas das questões que preocupavam os pensadores do antigo Egipto. Os assuntos que discutimos aqui estão todos relacionados com a morte e o defunto. Em primeiro lugar, é estabelecida uma das origens da morte: por um motivo não especificado no capítulo 175 , Set mata Osíris e provoca uma torrente de males. Embora a acção se passe na dimensão divina, Osíris representa, muito provavelmente, todos os seres humanos defuntos. Como arquétipo destes, Osíris é obrigado a confrontar-se com o isolamento e o desconforto da morte. Apesar de se tornar um espírito eficaz (akh) e de lhe ser dada paz de coração, estes elementos espirituais não compensam a perda de contacto com o mundo terreno. É possível que os próprios Egípcios se tenham questionado acerca da necessidade de uma conduta ética - que culminaria na psicostasia ilustrada no capítulo 125 do "Livro dos Mortos" - perante este destino desaprazível. Talvez o nível de exigência na conduta ética expresso no capítulo 125 espelhe isto mesmo. É também notável que no capítulo 175 não haja uma única referência à maet. Este capítulo não é moralizante, no sentido em que não "prega" a prática de maet, mas antes contempla questões existencialistas.

A última destas questões a ser aqui discutida é a do fim do mundo. Tal como em muitas outras culturas - incluindo a nossa -, desenvolveu-se a noção de que o mundo em que é possível a existência de uma sociedade estruturada de modo a permitir a existência de uma elite - no seio da qual se lucubraram estas reflexões - conheceria o seu fim. Não obstante, e possivelmente porque este capítulo se enquadra na literatura mortuária que procura beneficiar o defunto o mais possível, os autores egípcios mantiveram a esperança de que tal não acontecesse antes de milhões de anos se terem passado. 


\section{Notas}

(1) Trata-se de um compêndio de fórmulas mágicas colocado nos túmulos de funcionários e reis do Império Novo ao Terceiro Período Intermediário (1550-664 a. C.), cuja função era garantir ao defunto protecção contra as ameaças do mundo dos mortos e, como indica o nome egípcio $r(3) w n w$ prt $m$ hrw ("Fórmulas para sair de dia"), permitir-lhe que saísse da necrópole para o mundo dos vivos. Para uma introdução veja-se Erik HORNUNG, David LORTON (trad.), The Ancient Egyptian Books of the Afterlife, Ítaca e Londres: Cornell University Press, 1999, 13-22; Luis Manuel de ARAÚJO, "Livro dos Mortos", em Luís Manuel de Araújo (dir.), Dicionário do Antigo Egipto, Lisboa: Caminho, 2001, 513-17; e "Introduction", em Thomas George Allen, The Book of the Dead or Going Forth by Day: Ideas of the Ancient Egyptians Concerning the Hereafter as Expressed in Their Own Terms, Studies in Ancient Oriental Civilization 37, Chicago: Chicago University Press, 1974, 1-4. Todas as referências cronológicas aqui apresentadas têm por base a cronologia proposta em Ian SHAW (ed.), The Oxford History of Ancient Egypt, Nova lorque: Oxford University Press, 2000, 481-489.

(2) Daqui para a frente designado apenas por "capítulo 175 ".

(3) Texto hieroglífico da versão do "Livro dos Mortos" de Ani em E. A. Wallis BUDGE, The Book of the Dead: The Hieroglyphic Transcript of the Papyrus of Ani, the Translation into English, and An Introduction by E. A. Wallis Budge, Kessinger Publishing, 2005, 561-567. Dado que apenas dispomos desta versão do texto original, que contém vários erros, utilizamos as seguintes traduções feitas a partir desta e de outras outras versões do "Livro dos Mortos": traduções integrais: Robert Kriech RITNER, "Book of the Dead 175 (1.18): "Rebellion, Death and Apocalypse" ", em William W. Hallo (ed.), The Context of Scripture, vol. 1, Canonical Compositions from the Biblical World, Leiden, Boston: E. J. Brill, 2003, 27-30; Thomas George ALLEN, The Book of the Dead or Going Forth by Day: Ideas of the Ancient Egyptians Concerning the Hereafter as Expressed in Their Own Terms, Studies in Ancient Oriental Civilization, 37, Chicago: Chicago University Press, 1974, 183-185, e Paul BARGUET, Le Livre des Morts des Anciens Égyptiens, Paris: Les Éditions du Cerf, 1967, 260-263; traduções parciais: Leonard H. LESKO, "Ancient Egyptian Cosmogonies and Cosmology", em Byron E. Shafer (ed.), Religion in Ancient Egypt: Gods, Myths, and Religious Practice, Ítaca e Londres: Cornell University Press, 1991, 114; e John A. WILSON, "The Primeval Establishment of Order", em James B. Pritchard (ed.), Ancient Near Eastern Texts

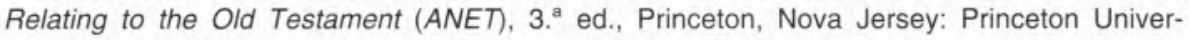
sity Press, 1969, 9-10.

(4) Robert Kriech RITNER, "Book of the Dead 175 (1.18): "Rebellion, Death and Apocalypse" ", em William W. Hallo (ed.), The Context of Scripture, 28. O texto não indica claramente quem fala. Na divisão dos diálogos seguimos John A. WILSON, "The Primeval Establishment of Order", em ANET, 9.

(5) Para uma discussão sobre os problemas na interpretação do discurso religioso egípcio veja-se John BAINES, "Interpretations of religion: logic, discourse, rationality", GM 76, (1984), 25-54.

(6) Veja-se, por exemplo, as fórmulas 219 e 600 dos "Textos das Pirâmides".

(7) Selected Papers (1956-73), Studia Aegyptiaca VII, Budapeste: Université Loránd Eötvös, Chaire de l'Histoire de l'Orient Ancien, 1981, 86-87, citado em Sherine M. ELSEBAIE, The Destiny of the World: A Study on the End of the Universe in the Light of Ancient Egyptian Texts, tese de mestrado, Graduate Department of Near and Middle Eastern Civilizations, Toronto: University of Toronto, 2000, 35 n. 105. 
(8) Elizabeth FROOD, John BAINES (ed.), Biographical Texts from Ramesside Egypt, Writings from the Ancient World 26, Atlanta: Society of Biblical Literature, 2007, $115 \mathrm{com}$ n. 118.

(9) Herman te VELDE, Seth, God of Confusion: A Study of His Role in Egyptian Mythology and Religion, Leiden: E. J. Brill, 1967, 86-7.

(10) Como explica Herman te Velde, a capacidade de um touro matar com as suas patas originou a que, na língua egípcia, hpš incluísse também os significados de "braço forte", "força", e designasse ainda a cimitarra. Ibidem, 87.

(11) Kurt SETHE, Die Altaegyptischen Pyramidentexte, vol. 2, Leipzig; J. C. Hinrischs'sche Buchhandlung, 1910, 329. Para uma interpretação diferente veja-se James P. ALLEN, The Ancient Egyptian Pyramid Texts, Writings of the Ancient World, Atlanta: Society of Biblical Literature, 2005, 185.

(12) Ver referenciação em Herman te VELDE, Seth, God of Confusion: A Study of His Role in Egyptian Mythology and Religion, 86.

(13) Ver tradução em Thomas George ALLEN, The Book of the Dead or Going Forth by Day: Ideas of the Ancient Egyptians Concerning the Hereafter as Expressed in Their Own Terms, 29. Ver também Herman te VELDE, Ibidem, 87.

(14) Herman te VELDE, Ibidem, 86.

(15) O ba tem a conotação de "manifestação" e da imagem que terceiros têm de um determinado individuo - algo que podemos resumir na palavra "presença", no sentido em que um indivíduo pode fazer sentir a sua presença naqueles que o rodeiam. $O$ que o texto nos diz é, portanto, que Set fica confinado a manifestar-se na barca solar onde a sua função é neutralizar as tentativas da serpente Apopis de imobilizar a barca solar, que simboliza a tendência natural do Nun para indiferenciar novamente o mundo diferenciado no processo de criação. Acerca do ba como manifestação de um deus vide Erik HORNUNG, Conceptions of God in Ancient Egypt: The One and the Many, Ítaca, Nova lorque: Cornell University Press, 1982, 138, e Joris BOURGHOUTS, "Divine Intervention in Ancient Egypt and its Manifestations (b; 'w)", em R. J. Demarée and J. J. Janssen (eds.), Gleanings from Deir el-Medina, Leiden: Nederlands Instituut voor het Nabije Oosten, 1982, 1-3. Sobre Set enquanto protector da barca solar veja-se Christian JACQ, O Mundo Mágico do Antigo Egipto, Porto: Asa, 1983, 142; e "Seth Repelling Apopis", em Herman te VELDE, Seth, God of Confusion: A Study of His Role in Egyptian Mythology and Religion, 99-108.

(16) Robert Kriech RITNER, "Book of the Dead 175 (1.18): "Rebellion, Death and Apocalypse" ", em William W. Hallo (ed.), The Context of Scripture, 2-9.

(17) Herman te VELDE, Seth, God of Confusion: A Study of His Role in Egyptian Mythology and Religion, 91-4.

(18) Como afirma Jan ASSMANN, "self-thematization, as seen in the reserve heads and mummy masks, must be interpreted as self-preservation." Em "Preservation and Presentation of Self in Ancient Egyptian Portraiture", em Peter der Manuelian (ed.), Studies in Honor of William Kelly Simpson, vol. 1, Boston: Museum of Fine Arts, 1996, 61.

(19) The Destiny of the World: A Study on the End of the Universe in the Light of Ancient Egyptian Texts, 35.

(20) A llha das Chamas era o lugar mitológico, também conhecido como Colina Primordial, a partir do qual se desencadeou o processo de criação. As chamas referem-se ao deus criador de características solares. 
Veja-se James P. ALLEN, The Ancient Egyptian Pyramid Texts, 434, e James P. ALLEN, Genesis in Egypt: The Philosophy of Ancient Egyptian Creation Accounts, Yale Egyptological Studies 2, New Haven: Yale University, 1988, 25.

(21) Robert Kriech RITNER, "Book of the Dead 175 (1.18): "Rebellion, Death and Apocalypse"”, em William W. Hallo (ed.), The Context of Scripture, 28.

(22) "Paradise", em Donald B. REDFORD (ed.), The Oxford Encyclopedia of Ancient Egypt, vol. 2, Nova lorque: Oxford University Press, 2001, 25.

(23) Como o sugere Julien RIES, Jeffrey HAIGHT e Annie S. MAHLER (trads.), "The Fall», em Lindasy Jones (ed.), Encyclopedia of Religion, 2. ${ }^{a}$ ed., Nova Iorque: Thomson Gale, 2005, 2961-2.

(24) Conceptions of God in Ancient Egypt: The One and the Many, 213.

(25) Este termo pode ser traduzido por "errado", "pecado", "mentira", "mal», e, em contexto político, por "ultraje" (Adof ERMAN, Hermann GRAPOW, Worterbuch der Aegyptischen Sprache, vol. 1, Berlim: Akademie-Verlag, 1971, 129). No fundo trata-se da antítese de maet.

(26) É até discutível até que ponto se pode concluir que o caos é a origem do mal. Mesmo na tentativa da serpente Apopis de engolir a barca solar - privando assim o mundo de uma das suas principais fontes de vida -, esta está apenas a materializar o ritmo natural do funcionamento do mundo; a ordem é a excepção e não a regra - por esse motivo, se não for mantida dissolve-se no caos. Embora os textos possam qualificar negativamente este processo, o caos não tem necessariamente uma dimensão moral. Podemos até estabelecer uma analogia com a nossa descrição do comportamento dos animais; embora por vezes digamos que um determinado animal não faz «mal», esse animal teria na verdade de ter uma consciência ética para o poder fazer - na realidade limita-se a seguir a sua natureza, tal como a serpente Apopis.

(27) Daqui para a frente designada apenas como "fórmula 1130".

(28) «Eu fiz todo o homem como o seu igual. Não ordenei que praticassem izft. Foram os seus corações que desobedeceram ao que eu disse" (iw ir.n.i s nb mi sn.nw.f $n$ wd.i ir.sn izft in ibw.sn hạddt.n.i). Adriaan de BUCK, The Ancient Egyptian Coffin Texts, vol. 7 (CT Vil), Chicago, Illinois: The University of Chicago Press, 1961, 463f-464b. David LORTON apresenta uma tradução com comentários em "God's Beneficent Creation: Coffin Texts Spell 1130, the Instructions for Merikare, and the Great Hymn to the Aton", SAK 20, (1993), 126-129.

(29) Palavras ditas pelo "Escondido de Nomes", "Senhor até ao Limite", que fala perante aqueles que silenciam a raiva durante a navegação do séquito: "Sigam em paz, enquanto eu repito para vocês os bons feitos que o meu coração fez para mim próprio no interior do $m h n$, de modo a silenciar izft (dd $m d w$ in štiw $r n<w>n b r$ - $d r d d$ hft sgrw nšn $m$ sqdwt šnwt wd' $m$ htp whm.i n.tn zpwy nfrwy ir.n n.i ib.i ds.i $m$-hnw mhn $n$ mrwt sgr<t> izft). CT VII, 461c-462c.

(30) Também esta questão parece não ter sido alvo de uma sistematização por parte dos antigos Egípcios, uma vez que no Livro da Vaca do Céu, registado em túmulos do Império Novo, a morte tem origem no massacre dos inimigos de Ré por parte dos humanos que procuravam convencer o deus Ré a regressar à terra após a rebelião destes últimos. Vide Geraldine PINCH, Egyptian Mythology: A Guide to the Gods, Goddesses, and Traditions of Ancient Egypt, Nova lorque: Oxford University Press, 2002, 75.

(31) Akh era o estado que o defunto alcançava após o seu ba se ter reunido com o seu ka. Este estado transfigurado permitia-lhe receber oferendas, e interferir no mundo dos vivos, 
de forma benfazeja ou malfazeja, assim como interceder por estes junto dos deuses. Por "eficácia" ser um dos significados subjacentes ao conceito de akh e devido às capacidades adquiridas pelo defunto com a sua transfiguração, akh é por vezes traduzido por "espírito eficaz". Veja-se Luís Manuel de ARAÚJO, "Akh", em Luís Manuel de Araújo (dir.), Dicionário do Antigo Egipto, Lisboa: Caminho, 2001, 40-41, R. J. DEMARÉE, The 3h ikr $n$ R'-stelae: on ancestor worship in ancient Egypt, Leiden: Nederlands Instituut voor het Nabije Oosten, 1983, 190-194, Florence Dunn FRIEDMAN, «Akh», em Donald B. Redford (ed.), The Oxford Essential Guide to Egyptian Mythology, Nova Iorque: Oxford University Press, 2002, 7-9; e ainda James P. ALLEN, Middle Egyptian Grammar: An Introduction to the Language and Culture of Hieroglyphs, Cambridge: Cambridge University Press, 2000, $31,95$.

(32) Leonard H. LESKO, "Ancient Egyptian Cosmogonies and Cosmology", em Byron E. Shafer (ed.), Religion in Ancient Egypt: Gods, Myths, and Religious Practice, 114.

(33) Sobre este ritual veja-se Ann Macy ROTH, "Opening of the Mouth", em Donald B. Redford (ed.), The Oxford Essential Guide to Egyptian Mythology, 293-8.

(34) Raymond O. FAULKNER, A Concise Dictionary of Middle Egyptian, Oxford: Griffith Institute, 1962, 144.

(35) J. M. Simões FERREIRA, "Condições de Habitabilidade ou Naturae Decor Segundo um "Canto de Carpideiras" do Império Médio", Cadmo 19, (2009), 231, reproduz um texto do reinado de Ramsés II de conteúdo sernelhante ao passo acima citado do capítulo 175 . Um excerto do cenotáfio de Seti I (1294-1279 a. C.) descreve a existência dos bas no mesmo tom: "como estas aves existem é com as suas caras como pessoas e a sua natureza como aves, uma delas falando para a outra com a linguagem do choro ( $m d w r m t)$, em James P. ALLEN, Genesis in Egypt: The Philosophy of Ancient Egyptian Creation Accounts, 1.

(36) Jan ASSMANN, David LORTON (trad.), Death and Salvation in Ancient Egypt, ítaca e Londres: Cornell University Press, 2005, 113-27.

(37) Veja-se, por exemplo, Mark SMITH, "Osiris and the Deceased", em Jacco Dieleman and Willeke Wendrich (eds.), UCLA Encyclopedia of Egyptology, Los Angeles, 2008, 2, http://escholarship.org/uc/item/29r70244 (acedido a 13 de Julho de 2010).

(38) Robert Kriech RITNER, "Book of the Dead 175 (1.18): "Rebellion, Death and Apocalypse" ", em William W. Hallo (ed.), The Context of Scripture, em William W. Hallo (ed.), The Context of Scripture, 28.

(39) Jan ASSMANN, Death and Salvation in Ancient Egypt, 114.

(40) O facto de até aqui haver um certo tabu, como afirma Assmann, pode-se dever à restrição operada pelo elemento da cultura egípcia que John Baines designa de decorum. Sobre este elemento veja-se "Decorum", em John BAINES, Visual and Written Culture in Ancient Egypt, Nova lorque: Oxford University Press, 2007, 14-29.

(41) No túmulo de Nikaiankh, da V dinastia (2494-2345 a. C.), é dito: «Eu designei um herdeiro para o dia em que for para o Ocidente - possa ser adiado". E no de Nenki, do reinado de Pepi II (2278-2184 a. C.), é afirmado: "vou fazer com que todos os vivos que estão sobre a terra tenham medo dos akhs que estão no Ocidente - possa estar longe". Estas duas referências foram estudadas em Hans GOEDICKE, "Early References to Fatalistic Concepts in Egypt", JNES 22, (1963), 187. Para uma interpretação diferente da segunda inscrição vide Nigel C. STRUDWICK, Texts from the Pyramid Age, Writings from the Ancient World, Atlanta: Society of Biblical Literature, 2005, 226.

(42) Dinastia em que ocorreram importantes inovações na religião egípcia, como a função destacada de Osíris nas crenças funerárias. Para uma discussão acerca das primeiras 
referências a este deus veja-se Andrey O. BOLSHAKOV, "Princess HM.T-R $(W)$ : The First Mention of Osiris?", CdÉ 67 (1992), 203-210, e Andrey O. Bolshakov, "Osiris in the Fourth Dynasty Again? The false door of Jntj, MFA 31.781", em Hedvig Györy (ed.), Mélanges offerts à Edith Varga, Budapeste: Bulletin du Musée Hongrois des Beaux-Arts, 2001, 65-80 .

(43) Adriaan de BUCK, The Ancient Egyptian Coffin Texts, vol. 6, Chicago, Illinois: The University of Chicago Press, 1956, 1911-o. Para a tradução de alguns termos recorremos a Raymond O. FAULKNER, The Ancient Egyptian Coffin Texts, vol. 2, 1977; reimpressão, Oxford: Aris and Phillips, 2004, 181.

(44) Thomas George ALLEN, The Book of the Dead or Going Forth by Day: Ideas of the Ancient Egyptians Concerning the Hereafter as Expressed in Their Own Terms, 87.

(45) Em duas outras versões do "Livro dos Mortos" os títulos são: "Fórmula para não morrer outra vez na necrópole», e «Fórmula para revivificação na necrópole, dando amor ao sh perante o deus grande que está no submundo". Robert Kriech RITNER, "Book of the Dead 175 (1.18): "Rebellion, Death and Apocalypse" ", em William W. Hallo (ed.), The Context of Scripture, $28 \mathrm{com}$ n. 2.

(46) A meu ver, a atitude de superar as dificuldades colocadas pelas condições de existência no outro mundo está presente em todos os períodos, independentemente da qualidade do equipamento funerário ser mais ou menos apurada.

(47) Na versão de Ani segue-se a frase "fiz com que ele enviasse os anciões". Segundo Robert Ritner esta declaração está deslocada, pelo que não a incluímos. Vide Robert Kriech RITNER, "Book of the Dead 175 (1.18): "Rebellion, Death and Apocalypse" , em William W. Hallo (ed.), The Context of Scripture, 28 n. 20.

(48) É Atum que está a falar. Porém, nas versões B3C e B6C o sujeito é o defunto.

(49) Em sentido literal, wrd ib significa "o que tem o coração cansado". Na descrição das desvantagens da velhice na Instrução de Ptah-hotep é dito, na linha 12, que "a força diminui para aquele que tem o coração cansado" (pḥty hr $* n$ wrd ib), o que ilustra bem o significado desta metáfora aplicada aos defuntos. Veja-se a versão hieroglífica da frase de Ptah-hotep em Christian JACQ, Les Maximes de Ptah-Hotep: l'enseignement d'un sage au temps des pyramides, Fuveau: La Maison de Vie, 2004, 114 com nota 14.

(50) Até aqui seguimos a versão B9C.

(51) Seguimos a versão B4C.

(52) CT VII, 467e-468b. Na tradução de alguns termos seguimos Raymond O. FAULKNER, The Ancient Egyptian Coffin Texts, vol. 3, 1978; reimpressão, Oxford: Aris and Phillips, 2004, 168; e Erik HORNUNG, Conceptions of God in Ancient Egypt: The One and the Many, 163.

(53) Raymond O. FAULKNER, A Concise Dictionary of Middle Egyptian, 7.

(54) CT VII, 468a.

(55) Jan ASSMANN, David LORTON (trad.), The Search for God in Ancient Egypt, Ítaca e Londres: Cornell University Press, 2001, 72.

(56) 'In é apenas omitido em B9C.

(57) Raymond O. FAULKNER, A Concise Dictionary of Middle Egyptian, 165.

(58) A experiência da perda de poder político e de privilégios sociais devido à descentralização do poder régio e enfraquecimento de várias instituições reais durante este período 
levou a que, na literatura do Império Médio, se reflectisse sobre este tema, possivelmente como uma forma de catarse. É por esta razão que sugiro que o fim do mundo seja descrito em comparação a esta experiência. Sobre o Primeiro Período Intermediário veja-se Stephan SEIDLMAYER, "The First Intermediate Period", em lan Shaw (ed.), The Oxford History of Ancient Egypt, 108-136.

(59) Vincent Arieh TOBIN, "The Teaching for King Merikare", em William Kelly Simpson (ed.), The Literature of Ancient Egypt: An Anthology of Stories, Instructions, Stelae, Autobiographies, and Poetry, Nova Haven e Londres: Yale University Press, 2003, 164.

(60) Erik HORNUNG, Conceptions of God in Ancient Egypt: The One and the Many, 54.

(61) Vincent Arieh TOBIN, "The Teaching for King Merikare», em William Kelly Simpson (ed.), The Literature of Ancient Egypt: An Anthology of Stories, Instructions, Stelae, Autobiographies, and Poetry, 164 n. 27, estabelece a mesma conexão.

(62) Veja-se por exemplo Siegfried MORENZ, Egyptian Religion, 169.

(63) A narrativa do Náufrago não é aqui tida em consideração por se distanciar do capítulo 175 e devido aos problemas de interpretação que apresenta. Mesmo que haja uma escatologia, esta cinge-se à ilha do ka e à serpente; o regresso do marinheiro ao Egipto sugere precisamente a continuação da existência do mundo. A questão da escatologia está também dependente da interpretação da frase $n$ zp $m$ s.k iw pn hpr $m$ nwy (Adriaan de BUCK, Egyptian Reading Book, vol. 1, Exercises and Middle Egyptian Texts, Leiden: E. J. Brill, 1948, 104 linha 11). Embora seja por vezes traduzida com o sentido de «não verás esta ilha outra vez, que se transformará em água", pode também ser interpretada como «nunca viste esta ilha, que veio à existência a partir da água".

(64) Erik HORNUNG, Conceptions of God in Ancient Egypt: The One and the Many, 93 com referências.

(65) Karol MYSLIWIEC, "Atum», em Donald B. Redford (ed.), The Oxford Essentiai Guide to Egyptian Mythology, 25. O próprio nome de Atum, i.tmw, "o que completa", "o que acaba", o apresenta como expressão do término do ciclo solar. James P. ALLEN, Genesis in Egypt: The Philosophy of Ancient Egyptian Creation Accounts, 9.

(66) Como o estado de wrd ib que caracteriza Osíris na fórmula 1130. Vide acima n. 49.

(67) Para os antigos Egípcios apenas os moraimente condenados estão mortos, isto é são privados da sua identidade e da capacidade de regenerarem com o deus sol, sofrendo um desmembramento físico e "psicológico" - os seus corações e bas, por exemplo, são-lhes removidos. Veja-se Erik HORNUNG, Conceptions of God in Ancient Egypt: The One and the Many, 160. Jacobus VAN DIJK apresenta uma útil introdução ao destino dos condenados em "Hell", em Donald B. Redford (ed.), The Oxford Encyclopedia of Ancient Egypt, vol. 2, 90. É ainda interessante observar que os tormentos de que os condenados são vítimas constituem igualmente uma ameaça para os justificados. A boa conduta moral em vida não garante a priori uma existência tranquila após a morte. Podemos ainda perguntar se o contrário também é possivel, isto é se os condenados podem escapar ao seu castigo do mesmo modo que os justificados podem ser torturados pelos demónios do submundo.

${ }^{(68)}$ Erik HORNUNG, Conceptions of God in Ancient Egypt: The One and the Many, 96.

(69) James P. ALLEN, Genesis in Egypt: The Philosophy of Ancient Egyptian Creation Accounts, 2. Sobre a união de Ré com Osíris veja-se ainda Erik HORNUNG, Conceptions of God in Ancient Egypt: The One and the Many, 93-6.

(70) Thomas George ALLEN, The Book of the Dead or Going Forth by Day: Ideas of the Ancient Egyptians Concerning the Hereafter as Expressed in Their Own Terms, 27. Um 
precursor quase idêntico desta glosa está presente na fórmula 335 dos "Textos dos Sarcófagos", onde duas das várias versões que contêm esta fórmula fazem corresponder o amanhã a Atum. Esta variação dever-se-á certamente à proximidade semântica entre Ré e Atum. Vide Raymond O. FAULKNER, The Ancient Egyptian Coffin Texts, vol. 1, 262 com nota 7 .

(71) Thomas George ALLEN, The Book of the Dead or Going Forth by Day: Ideas of the Ancient Egyptians Concerning the Hereafter as Expressed in Their Own Terms, 28. A transliteração do mesmo passo na fórmula 335 dos "Textos dos Sarcófagos" é a seguinte: ir

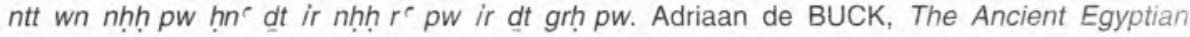
Coffin Texts, vol. 4, Chicago, Illinois: The University of Chicago Press, 1951, 201d-203b.

(72) Sobre este último aspecto veja-se Abd-el-Mohsen BAKIR, «A Further Re-Appraisal of the Terms: Nḥh and Dt, JEA 60, (1974), 253. Acerca da dialéctica entre estase e dinamismo vide James P. ALLEN, Genesis in Egypt: The Philosophy of Ancient Egyptian Creation Accounts, 25.

(73) The Search for God in Ancient Egypt, 76.

(74) Veja-se, por exemplo, Alan GARDINER, Egyptian Grammar: Being an Introduction to the Study of Hieroglyphs, $3 .^{a}$ ed. rev., Oxford: Griffith Institute, 1957, 219; e James P. ALLEN, Middle Egyptian Grammar: An Introduction to the Language and Culture of Hieroglyphs, 149. Note-se que no que respeita a terminologia gramatical, esta pode variar de gramática para gramática.

(75) Exemplos dos dois aspectos são: ink rdi pri s 2 htp $(w y)$, "eu sou aquele que fez dois homens sairem satisfeitos" (perfectivo), e ink dd pry s 2 htp(wy) m priw $n r(\jmath) . f$, "eu sou um que faz dois homens partirem satisfeitos com o que sai da sua boca" (imperfectivo). Em Boyo G. OCKINGA, A Concise Grammar of Middle Egyptian, Mainz am Rhein: Verlag Philipp von Zabern, 2005, 65.

(76) The Search for God in Ancient Egypt, 78.

(77) E. P. UPHILL, «The Ancient Egyptian View of World History", em John Tait (ed.), "Never had the Like Ocurred": Egypt's views of its past, Londres: University College London Press, 2003, 19, sugere que estas serpentes possam ser similares à serpente $m \mathfrak{m} n$, também designada de Uroboros (sobre esta serpente vide Erik HORNUNG, Conceptions of God in Ancient Egypt: The One and the Many, 160 passim). A serpente Uroboro representa a ciclicidade do tempo. A imagem da serpente com a cauda na boca e que muda de pele transmite precisamente este conceito; a forma circular sugere continuidade, enquanto a pele velha simboliza o que foi completado, o que pertence ao passado. No papiro de Heriuebkhet, da XXI dinastia (1069-945), existe uma representação pictórica que conjuga o renascimento do deus sol dentro desta serpente apoiada na vaca celeste representando o Ocidente, que por sua vez encima os leões do ontem e do amanhã (vide Rogério SOUSA, Iniciação e Mistério no Antigo Egipto: O caminho de transformação do coração, Lisboa: Ésquilo, 2009, 34).

(78) Conceptions of God in Ancient Egypt: The One and the Many, 178.

(79) Vide n. 77.

(80) Outras formas incluem rãs (no caso dos deuses que representam o caos primordial na cosmogonia de Hermopólis; vide José das Candeias SALES, As Divindades Egípcias: uma chave para a compreensão do Egipto antigo, Lisboa: Editorial Estampa, 1999, 69) e larvas. Estas últimas são, numa das versões do capítulo 175, a forma assumida por Atum e Osíris (Robert Kriech RITNER, "Book of the Dead 175 (1.18): "Rebellion, Death and Apocalypse"», em William W. Hallo (ed.), The Context of Scripture, 28 n. 21). 
(81) Geraldine PINCH, Egyptian Mythology: A Guide to the Gods, Goddesses, and Traditions of Ancient Egypt, 111, e fórmula 252 dos "Textos da Pirâmide" de Neit (tradução em James P. ALLEN, The Ancient Egyptian Pyramid Texts, Writings from the Ancient World, Atlanta: Society of Biblical Literature, 2005, 329).

(82) "The Ancient Egyptian View of World History", em John Tait (ed.), "Never had the Like Ocurred": Egypt's views of its past, 22.

(83) Como a fórmula 1130 que seria recitada no festival de um deus solar. David LORTON, "God's Beneficent Creation: Coffin Texts Spell 1130, the Instructions for Merikare, and the Great Hymn to the Aton», 144.

(84) Um dos textos que melhor atestam esta contemplação é o passo do Papiro Chester Beatty IV, datado do Império Novo, que reflecte sobre a imortalidade dos escribas:

Quanto aos escribas letrados,

[...]

Os seus pórticos e mansōes ruíram,

Os seus sacerdotes do ka [desapareceram];

As suas pedras tumulares estão cobertas pelo solo,

As suas sepulturas foram esquecidas.

[...]

O homem decompōe-se, o seu corpo é pó,

Todos os seus pereceram.

Tradução de Miriam LICHTHEIM, Ancient Egyptian Literature, vol. 2, The New Kingdom, Berkeley, Los Angeles, Londres: University of California Press, 1976, 176-177. 